\title{
The Effect of Forest Activities on the Movement Skill and Prosocial Behavior of Children with a Developmental Disability
}

\author{
Yong Sun Jo ${ }^{1}$, Chang Duk Koo ${ }^{2}$, Seuk Hyang Hong ${ }^{1 *}$, and Jin Hee You ${ }^{3}$ \\ ${ }^{1}$ Department of Forest Therapy, Chungbuk National University, Cheongju, South Korea \\ ${ }^{2}$ Department of Forest Science, Chungbuk National University, Cheongju, South Korea \\ ${ }^{3}$ Treatment Center, Daniel School, Seoul, South Korea
}

\begin{abstract}
The purpose of this study was to examine the effects of forest activities on the movement skills, fine muscle functions and prosocial behaviors of children with a developmental disability. 12 children, aged 8 to 10, participated in this study; all of whom were either autistic or had an intellectual disability. The participants were divided in half and designated to either the experimental group or to the control group. The Forest Activity program was carried out once a week (from 10 a.m. to 12 p.m) for 10 weeks in a forest near D school in Seoul. Gross Motor Skill (MSTB-B), Fine Motor Skill, and prosocial behavior (PBSYC) was used as measuring tools to test the effects of the Forest Activity program on the participants. The application of the Forest Activity program showed improvements in flexibility and equivalence areas of Gross Motor Skill; as well as improved fine motor skills in accuracy and stability areas of small muscle function; and finally, there was an increase of prosocial behavior in 5 areas out of a total 7 areas (leadership, providing assistance, communication, empathy, proximity seeking). This study supports previous research in demonstrating the effectiveness of programs applying forest activities, such as the forest healing program, to enhance physical and mental stability.
\end{abstract}

Key words: fine muscle skills, forest activity programs, movement skill, social skills

\section{I . Introduction}

Developmental disability refers to the impairment of an individual's mental or physical functions due to genetic or environmental factors; this can result in mental retardation, learning difficulties, cerebral palsy, brain injury, and so on (Lim et al., 2005). Individuals with a developmental disability display impediments to learning, display a lack of metaphysical thinking ability, and are slow in learning (Noh, 2009). Group interaction only occurs under controlled circumstances which results in limited relationships (Yoo, 2000). Children who have a developmental disability and who live in specialized centers, display low physical abilities. An explanation for this is that they tend to not participate in physical activities (Choi, 2002), and that circumstance does not allow them to act without their parents. To raise the quality of their life and assist them with social integration, they need help with their occupations

Received on October 29, 2016. Revised on November 18, 2016. Accepted on November 22, 2016.

*Corresponding author: nahong22@hanmail.net and independence after becoming adults (Cho, 1999). There are facilities and specialized schools that help in these areas and which provide aid for their welfare and offer rehabilitation. There are a number of studies dealing with child developmental disorders in the multidisciplinary fields such as horticulture (Lee, 2011), art (Park, 2007), music and physical education (Hwang, 2010). However, the influence of participating in forest activities on improving physical activity and social skills of children with a developmental disability has not been fully investigated. This study aims to find out whether forest activities improve the capacity for exercise and socialness by communicating with friends of the students.

\section{Method and materials}

\section{Participants}

The study participants were 12 children from D specialized school in Seoul, all of whom have been diagnosed with a developmental disability at a second or third degree. The participants were randomly assigned into two groups, the 
experimental group (E1-E6), or the control group. According to the data provided from the school, their mental ages ranged from 4-6 years old. We explained the purpose and contents of this study to the teachers and legal guardians of the participants in order to seek consent from them beforehand. The characteristics of participants are mentioned in Table 1 below.

\section{Description of the forest activity program}

Through the use of forest activities, this program aimed to improve the physical and social abilities of children with a developmental disability. The term forest activities refers to the physical activities that were done in forests, such as games, forest trail walks, forest healing activities, etc. According to previous research, phytoncide, negative ions, and nature sounds of forests can calm excitement (Park, 2014), and even looking at forest scenes can stabilize emotions. To specifically achieve FMS development, the 'smile face making' activity was used.
This was a repetitive routine used at the end of each session, natural objects were made to become gradually smaller over time, therefore requiring more delicate use of muscle. Additionally, special care was given to encourage the participants to engage in peer communication, as well as deepen their relationships with their teachers and the researchers in order to achieve the social goal. The total 10 sessions were divided into 3 stages; the initial stage was comprised of $1^{\text {st }}-2^{\text {nd }}$ sessions, the core stage had the following $2^{\text {nd }}-8^{\text {th }}$ sessions, and the final concluding stages had the $9^{\text {th }}-10^{\text {th }}$ session. These stages are summarized in Table 2.

\section{Research design}

After designating the participants and training the assistants for the forest activities, we pre-tested the participants. The program was adjusted every Sunday from $10 \mathrm{a} . \mathrm{m}$. to $12 \mathrm{p} . \mathrm{m}$. in a forest near the D welfare school. A post-test was held afterwards.

Table 1. Characteristics of participants

\begin{tabular}{|c|c|c|c|c|c|c|c|c|c|c|c|c|}
\hline \multirow{2}{*}{ Group } & \multicolumn{3}{|c|}{ Chronological age } & \multicolumn{3}{|c|}{ Mental age } & \multicolumn{2}{|c|}{ Disability } & \multicolumn{2}{|c|}{ Degree of disability } & \multicolumn{2}{|c|}{ Total } \\
\hline & 8 & 9 & 10 & 4 & 5 & 6 & Intellectual & Autism & 2 & 3 & Freq. & $\%$ \\
\hline Experimental group & 2 & 2 & 2 & 2 & 1 & 3 & 5 & 1 & 1 & 5 & 6 & 100 \\
\hline Control group & 1 & 3 & 2 & 2 & 2 & 2 & 5 & 1 & 2 & 4 & 6 & 100 \\
\hline
\end{tabular}

Table 2. Forest activity programs (summary).

\begin{tabular}{|c|c|c|c|}
\hline Turn & Programs & Activities & Healing factor \& Program objective \\
\hline $1-2$ & $\begin{array}{l}\text { Orientation } \\
\text { A forest with amusement }\end{array}$ & $\begin{array}{l}\text { Greeting } \\
\text { Sliding a slope } \\
\text { Hunting spider web } \\
\text { Health to drinking a cup of tea } \\
\text { Making a smiling face }\end{array}$ & $\begin{array}{l}\text { Enhancement of muscle exercise ability } \\
\text { Prosocial behaviour enhancement }\end{array}$ \\
\hline $3-8$ & $\begin{array}{l}\text { Meeting Forests } \\
\text { Exploring the forest } \\
\text { Enhancement program of muscle exercise } \\
\text { ability and sociality }\end{array}$ & $\begin{array}{l}\text { Navigating the fall forest paths and walking } \\
\text { Remove the bomb, a chestnut burr } \\
\text { Gathering together the raindrop } \\
\text { Strong body, Strong mind } \\
\text { Collecting maple leaves } \\
\text { Rescue of baby squirrels } \\
\text { Open the forest gate } \\
\text { The ant and aphids } \\
\text { Health to drinking a cup of tea } \\
\text { Making a smile face }\end{array}$ & $\begin{array}{l}\text { Feeling changes in the fall while walking } \\
\text { through the woods } \\
\text { A forest with amusement as sociality } \\
\text { enhancement }\end{array}$ \\
\hline
\end{tabular}


Table 3. Research design and relevant measure.

\begin{tabular}{|c|c|c|c|c|c|}
\hline Division & Period & Pre-test & Program execution & Post-test & Test item \\
\hline $\begin{array}{l}\text { Experimental group } \\
(\mathrm{N}=6)\end{array}$ & $2015.10 .09-12.13$ & ()$^{2}$ & () & () & $\begin{array}{c}\text { MSTB } \\
\text { FMS } \\
\text { PBSYC }\end{array}$ \\
\hline $\begin{array}{l}\text { Control group } \\
(\mathrm{N}=6)\end{array}$ & (for 10 weeks) & () & $\otimes^{\mathrm{y}}$ & () & $\begin{array}{c}\text { MSTB } \\
\text { FMS } \\
\text { PBSYC }\end{array}$ \\
\hline
\end{tabular}

${ }^{\mathrm{z}}(\mathrm{O})$ : practice, ${ }^{\mathrm{y}} \otimes$ : non practice.

MSTB-B: Movement Skill Test Battery-B.

FMS: Fine Muscle Skills assessment.

PBSYC: Prosocial Behavior Scale for Young Children.

To increase the reliability of the assessments, a specialized teacher participated throughout the whole process of participant selection, pre-test, program, observation assesment and post-test (Table 3).

\section{Measurements and tools}

1) Measurement tool for exercise capacity

We used both gross and fine motor skill measurement tools for this study. All measurements were executed under the control of the chief researcher with the help of 3 assistants at the same time and at the same site.

First, the Movement Skill Test Battery (MSTB), translated by Park (1993), was used to measure the muscular strength and muscular endurance development, which are parts of gross-motor skills. This tool is composed of type A (MSTB-A) and type B (MSTB-B). MSTB-A contains 4 subordinate tests which are used to measure several aspects of fine motor skills, such as the coordination capacity between the eyes and the hands, as well as sight ability. MSTB-B contains 8 subordinate tests used to measure muscular strength, muscular endurance development, flexibility, sense of balance and agility. We used Type B to measure gross-motor skills.

Next, to measure Fine Muscle Skill (FMS), 'Fine Muscle Skills assessment tool' of Kang (2002) was used. It has 3 subordinate tests which are Accuracy, Rapidity, and Stability; the rating is composed of the Likert-type scale 4 , which has a score of 0 to 3 . A score of 3 is the highest achievable rank in evaluating the ability of success and the use of their body, while 1 demonstrates the lowest standard of performance. The reliability of this tool is .703 Cronbach $\alpha$.
2) Measurement tool for Sociality.

Prosocial Behavior Scale for Young Children (PBSYC) by Kim (2003) for the mental age of 4 to 6 year olds was used to evaluate the social ability of developmentally disabled children. PBSYC is composed of 7 sections with a total 42 questions. 8 questions within guidance sector, 9 questions for giving aid, 7 for communication section, 6 for active consideration, 5 for approach section, 3 for sharing section, and 4 for emotion control and empathy sections. Each question was evaluated by the Likert-type scale 5 which scores on a range of 5 , meaning 'very likely', to a score of 1 , meaning 'very unlikely'; the higher the score is, the higher the sociability of the participant. This was done by the participant's homeroom teachers who were able to observe them closely within different circumstances and could evaluate each of their tendencies with more accuracy. The reliability of this tool was 0.99 Cronbach $\alpha$ as a whole, and among each section it was 0.93-0.98.

\section{3) Observation report}

To achieve better statistical reliability, it would have been better to have had more participants, but the possibility of achieving a larger participant pool for the program were low due to a lack of assistants and participants. Instead, to compensate for the quantity of the participants, we used detailed observation reports to improve the quality of the research. To achieve this, we filmed each program and wrote documents.

\section{Data analysis}

First, to check the normality of each test result Shapiro-Wilk test was held before we started the program. MSTB-B didn't 
meet the normal distribution while the other 2 did. So we adjusted Mann-Whitney U test for MSTB-B and Independent samples t-test for FMS and PBSYC to the pretest results of both controled and experimental groups so that we proved homogeneity between them.

Second, to examine the effects of forest activities on grossmotor skills, Wilcoxon Signed Rank test, a non-parametric test, was held. We compared the average (M) and standard deviation (SD) between pre-test and post-test results and checked out if there were any statistically significant differences in the experimental group.

Third, to examine the effects of forest activities on FMS, we compared the average (M) and standard deviation (SD) between pre-test and post-test results of the experimental group and analyzed the covariance (ANCOVA) to see if there was a statistically significant difference.

Fourth, to examine the effects of forest activities on the development of prosocial behavior in the experimental group, we compared the average (M) and standard deviation (SD) between pre-test and post-test results of the prosociality assessment tool and analyzed the covariance (ANCOVA) to see if there was a statistically significant difference.

SPSS 18.0 for Windows was used throughout the process.

\section{Results and discussion}

1. Result of the pre-test toward homogeneity between two groups

Before we started the program, a pre-test to ascertain homo- geneity was conducted between the control group and the experimental group. The result of Mann-Whitney $U$ test of the MSTB subordinate sections was not statistically significant ( $p>0.05$ ). Result of Independent samples t-test towards FMS and PBSYC showed that the possibility of statistical significance was $p>0.05$. Therefore, homogeneity was found in both the control group and the experimental group (Table 4).

\section{Changes of Gross Motor Skills (GMS)}

Wilcoxon signed rank test related to GMS showed statistically significant improvements within the experimental group in 'bending forward' ( $\mathrm{p}=0.041$ ) (an indicator of flexibility), 'walk on a board' ( $p=0.028)$ and 'balance with eyes open' $(p=0.024)$ (indicators for balance) whereas the controlled group showed no statistically significant changes except for 'round-run' ( $\mathrm{p}=0.046$ ) (an indicator for quick- ness). As it states on Table 5 , the experimental group showed a larger difference between pre and post test results in every section compared to the control group, especially within the 4 sections where the improvements were statistically significant.

\section{Changes of Fine Motor Skills (FMS)}

Following the adjustment of the healing factors, the effects on the participants FMS were assessed. The average and standard deviation of pre and post test results of the control group and the experimental group are on Table 6 and the covariance structure analysis results are on Table 7.

On table 6, FMS of the experimental group showed a large increase of the average $(\mathrm{M}=2.37, \mathrm{SD}=0.44)$ and control group

Table 4. Results of scale by homogeneity test.

\begin{tabular}{|c|c|c|c|c|c|c|c|c|}
\hline & \multirow{2}{*}{\multicolumn{2}{|c|}{ Scale (unit) }} & \multicolumn{2}{|c|}{ Experimental group } & \multicolumn{2}{|c|}{ Control group } & \multirow{2}{*}{$\mathrm{z}$ or $\mathrm{t}$} & \multirow{2}{*}{$\mathrm{p}$} \\
\hline & & & Mean & SD & Mean & SD & & \\
\hline \multirow{4}{*}{$\operatorname{MSTB}^{z}$} & Muscular endurance & Long jump (cm) & 59.50 & 22.30 & 76.30 & 45.30 & -0.64 & $0.522^{\mathrm{NS}}$ \\
\hline & Flexibility & Bending forward (cm) & 27.70 & 2.30 & 23.50 & 10.70 & 0.00 & $1.000^{\mathrm{NS}}$ \\
\hline & Equivlance & Walking board (score) & 6.80 & 5.20 & 6.80 & 8.80 & -0.48 & $0.629^{\mathrm{NS}}$ \\
\hline & Quickness & Round-run (second) & 32.00 & 18.10 & 27.00 & 20.00 & -0.97 & $0.332^{\mathrm{NS}}$ \\
\hline \multicolumn{3}{|c|}{ FMS (Likert score) ${ }^{\mathrm{y}}$} & 1.72 & 0.92 & 2.17 & 0.84 & -0.87 & $0.404^{\mathrm{NS}}$ \\
\hline \multicolumn{3}{|c|}{ PBSYC (Likert score) ${ }^{\mathrm{y}}$} & 2.63 & 0.66 & 2.31 & 0.63 & -0.86 & $0.409^{\mathrm{NS}}$ \\
\hline
\end{tabular}

\footnotetext{
${ }^{\mathrm{NS}}$ Not significant.

zby Mann-Whitney U test.

${ }^{\mathrm{y}}$ by Independent samples t-test.
} 
Table 5. Comparison of means in each area by Wilcoxon signed rank test (MSTB).

\begin{tabular}{|c|c|c|c|c|c|c|}
\hline & \multirow{2}{*}{ Sub-areas } & & Pre & Post & \multirow{2}{*}{$\mathrm{Z}$} & \multirow{2}{*}{$\mathrm{p}$} \\
\hline & & & $\mathrm{M}(\mathrm{SD})$ & $\mathrm{M}(\mathrm{SD})$ & & \\
\hline \multirow{4}{*}{$\begin{array}{l}\text { Muscular } \\
\text { endurance }\end{array}$} & Long jump & Experimental group & $59.50(22.36)$ & $78.80(17.55)$ & -1.78 & 0.075 \\
\hline & \multirow{2}{*}{ Sit-up } & Experimental group & $2.00(4.42)$ & $5.60(2.06)$ & -1.89 & 0.058 \\
\hline & & Control group & $7.50(6.25)$ & $8.30(5.98)$ & -0.96 & 0.336 \\
\hline & Push-ups & Control group & $4.50(6.31)$ & $3.80(6.33)$ & -0.82 & 0.414 \\
\hline \multirow{2}{*}{ Flexibility } & \multirow{2}{*}{ Bending forward } & Experimental group & $27.60(2.25)$ & $48.30(12.91)$ & -2.04 & $0.041^{*}$ \\
\hline & & Control group & $23.50(10.74)$ & $22.60(11.92)$ & -0.41 & 0.684 \\
\hline \multirow{3}{*}{ Equivlance } & Walking board & Experimental group & $6.80(5.23)$ & $14.80(4.40)$ & -2.20 & $0.028^{*}$ \\
\hline & \multirow{2}{*}{$\begin{array}{l}\text { Balance } \\
\text { (blind) }\end{array}$} & Experimental group & $2.50(1.76)$ & $4.10(1.83)$ & -1.63 & 0.102 \\
\hline & & Control group & $7.50(6.77)$ & $8.00(6.72)$ & -0.41 & 0.684 \\
\hline \multirow{4}{*}{ Quickness } & \multirow{2}{*}{ Round-run } & Experimental group & $32.00(18.05)$ & $30.00(15.84)$ & -0.95 & 0.343 \\
\hline & & Control group & $27.00(20.00)$ & $33.80(17.73)$ & -1.99 & $0.046^{*}$ \\
\hline & \multirow{2}{*}{$\begin{array}{l}\text { A shift in the position } \\
\text { of the body }\end{array}$} & Experimental group & $4.30(2.50)$ & $5.30(2.06)$ & -0.38 & 0.705 \\
\hline & & Control group & $12.60(12.20)$ & $9.00(10.64)$ & -0.14 & 0.891 \\
\hline
\end{tabular}

*Significant at $\mathrm{p}<0.05$ by Wilcoxon signed rank test.

Table 6. Comparison of the means of the overall FMS scores (FMS).

\begin{tabular}{|c|c|c|c|c|}
\hline & \multirow{2}{*}{ Group } & Pre & Post & Adjusted means \\
\hline & & $\mathrm{M}(\mathrm{SD})$ & $\mathrm{M}(\mathrm{SD})$ & $\mathrm{M}(\mathrm{SE})$ \\
\hline \multirow{2}{*}{ Overall } & Experimental group & $1.72(0.92)$ & $2.37(0.44)$ & $2.50(0.12)$ \\
\hline & Control group & $2.17(0.84)$ & $2.06(0.72)$ & $1.92(0.12)$ \\
\hline
\end{tabular}

Table 7. Covariance analysis of the overall FMS scores of each group.

\begin{tabular}{|c|c|c|c|c|c|}
\hline Covariance & 3.64 & 1 & 3.64 & 39.19 & $0.000^{* * *}$ \\
\hline Residual & 0.84 & 9 & 0.09 & & \\
\hline Sum & 66.36 & 12 & & & \\
\hline
\end{tabular}

${ }^{*, * * * * * *}$ Significant at $\mathrm{p}<0.05, \mathrm{p}<0.01, \mathrm{P}<0.001$ by ANCOVA.

showed little change $(\mathrm{M}=2.06, \mathrm{SD}=0.72)$. The adjusted means average showed a higher score in the experimental group $(\mathrm{M}=2.50)$ compared to the control group $(\mathrm{M}=1.92)$.

Table 7 is the result of covariance analysis to confirm whether the change of average was statistically significant. We set the pre test as a covariate variable and analyzed it against the post test. The $\mathrm{F}$ value of the covariate variable (pre test) was $39.19(p<0.001)$. We concluded that the FMS pre test score 
affected the post test score. Following the application of the covariate variable in forest activities to the two groups, analysis results showed that the F value scored 7.73 and probability of significance was $0.021(p<0.05)$, we concluded that FMS change had a significant difference between the two groups.

Table 8 compares subordinate section averages and standard deviations in each area by setting the pre test as a covariate variable and executing ANCOVA. The experimental group had statistically significant increases of accuracy, stability and overall scores $(\mathrm{p}<0.05)$.

\section{Changes of sociality}

We assessed the effects of forest activities on prosocial behavior of children with developmental disabilities. The average and standard deviation of pre-post test results of both groups appears on Table 9 and the result of covariance analysis is on Table 10.

About the total score of prosocial behaviour, as you can see in Table 9, after applying the program, the experimental group's average $(\mathrm{M}=3.13, \mathrm{SD}=0.47)$ increased a huge amount compared to the controlled group $(\mathrm{M}=2.36, \mathrm{SD}=0.61)$ as well as the average after adjustment (experimental group: $\mathrm{M}=3.01$, controlled group: $\mathrm{M}=2.49$ )

As it can be seen in Table 10, to confirm the validity of the changes of averages, we set the pre test as a covariate variable and analyzed it against the post test. The $\mathrm{F}$ value of the covariate variable (pre test) was 35.12 ( $\mathrm{p}<0.001$ ). We concluded that prosocial behaviour pre test score significantly affected the post test score. Under control of the pre test score we analyzed the effect after applying the forest activities to the two

Table 8. Comparison of means about each area by ANCOVA (FMS).

\begin{tabular}{|c|c|c|c|c|c|c|}
\hline & \multirow{2}{*}{ Sub-areas } & Pre & Post & Adjusted means & \multirow{2}{*}{$\mathrm{F}$} & \multirow{2}{*}{$\mathrm{p}$} \\
\hline & & $\mathrm{M}(\mathrm{SD})$ & $\mathrm{M}(\mathrm{SD})$ & $\mathrm{M}(\mathrm{SE})$ & & \\
\hline \multirow{2}{*}{ Accuracy } & Experimental group & $1.78(0.86)$ & $2.61(0.39)$ & $2.73(0.15)$ & \multirow{2}{*}{11.24} & \multirow{2}{*}{$0.008^{* *}$} \\
\hline & Control group & $2.17(0.86)$ & $2.11(0.83)$ & $1.98(0.15)$ & & \\
\hline \multirow{2}{*}{ Rapidness } & Experimental group & $1.72(1.08)$ & $2.28(0.53)$ & $2.39(0.22)$ & \multirow{2}{*}{1.13} & \multirow{2}{*}{0.316} \\
\hline & Control group & $2.33(0.76)$ & $2.17(0.69)$ & $2.05(0.22)$ & & \\
\hline \multirow{2}{*}{ Stability } & Experimental group & $1.67(1.01)$ & $2.22(0.50)$ & $2.32(0.09)$ & \multirow{2}{*}{16.41} & \multirow{2}{*}{$0.003^{* *}$} \\
\hline & Control group & $2.00(1.05)$ & $1.89(0.75)$ & $1.79(0.09)$ & & \\
\hline \multirow{2}{*}{ Overall } & Experimental group & $1.72(0.92)$ & $2.37(0.43)$ & $2.50(0.11)$ & \multirow{2}{*}{7.73} & \multirow{2}{*}{$0.021^{*}$} \\
\hline & Control group & $2.17(0.84)$ & $2.06(0.72)$ & $1.92(0.11)$ & & \\
\hline
\end{tabular}

${ }^{*, * *}$ Significant at $\mathrm{p}<0.05, \mathrm{p}<0.01$, by ANCOVA.

Table 9. Comparison of means about overall score (PBSYC).

\begin{tabular}{|c|c|c|c|c|}
\hline & \multirow{2}{*}{ Group } & Pre & Post & Adjusted means \\
\hline & & $\mathrm{M}(\mathrm{SD})$ & $\mathrm{M}(\mathrm{SD})$ & $\mathrm{M}(\mathrm{SE})$ \\
\hline \multirow{2}{*}{ Overall } & Experimental group & $2.63(0.66)$ & $3.13(0.47)$ & $3.01(0.11)$ \\
\hline & Control group & $2.31(0.63)$ & $2.37(0.61)$ & $2.49(0.11)$ \\
\hline
\end{tabular}

Table 10. Covariance analysis for group (overall score of PBSYC).

\begin{tabular}{lccccc}
\hline \multicolumn{1}{c}{ Distributed source } & Sum of squares & Degree of freedom & Square mean & F & p \\
\hline Covariance & 2.35 & 1 & 2.36 & 35.12 & $0.000^{* * *}$ \\
Group & 0.76 & 1 & 0.76 & 11.27 & $0.008^{* *}$ \\
Residual & 0.60 & 9 & 12 & 0.07 & \\
\hdashline Sum & 95.19 & & \\
\hline
\end{tabular}

${ }^{* * * * * *}$ Significant at $\mathrm{p}<0.01, \mathrm{p}<0.001$ by ANCOVA. 
groups. The $\mathrm{F}$ value scored 11.27 and significance probability was $0.008(p<0.01)$, therefore we concluded that the change of prosocial behavior score has a significant difference between two groups. Table 11 is a comparison of the subordinate sections'averages and standard deviations of each area which uses the pre test as a covariate and executes ANCOVA. The experimental group had statistically significant increases of 5 sections $(\mathrm{p}<0.05)$ among a total 7 , which are leadership, providing assistance, communication, active consideration, attempt to approach and an overall increase $(\mathrm{p}<0.05)$ as well.
5. Observation report for each participant

\section{1) Related to GMS}

At the initial stage, participants E1 and E3 had difficulties in their mobility, while the other participants were more able. By the end of the program, E1 succeeded to carry out jumping with two feet together, walking along a rope, etc. E3 had progress in some areas of movement.

2) Related to FMS

At the initial stage, all participants had difficulties with

Table 11. Comparison of means about each area by ANCOVA (PBSYC).

\begin{tabular}{|c|c|c|c|c|c|c|}
\hline \multicolumn{2}{|c|}{ Sub-areas } & \multirow{4}{*}{$\begin{array}{c}\text { Pre } \\
M(\mathrm{SD}) \\
2.85(0.55) \\
2.42(0.78)\end{array}$} & \multirow{4}{*}{$\begin{array}{c}\text { Post } \\
\text { M (SD) } \\
3.19(0.40) \\
2.46(0.72)\end{array}$} & \multirow{4}{*}{$\begin{array}{c}\text { Adjusted means } \\
\mathrm{M}(\mathrm{SE}) \\
3.01(0.08) \\
2.64(0.08)\end{array}$} & \multirow{4}{*}{$\begin{array}{c}\mathrm{F} \\
8.44\end{array}$} & \multirow{4}{*}{$\begin{array}{c}\mathrm{p} \\
0.017^{*}\end{array}$} \\
\hline \multirow{3}{*}{ Leadership } & Fxnerimental oroun & & & & & \\
\hline & Experimental group & & & & & \\
\hline & Control group & & & & & \\
\hline \multirow{2}{*}{ Giving help } & Experimental group & $2.17(0.74)$ & $3.07(0.43)$ & $3.07(0.22)$ & \multirow{2}{*}{8.01} & \multirow{2}{*}{$0.020^{*}$} \\
\hline & Control group & $2.17(0.74)$ & $2.19(0.71)$ & $2.19(0.22)$ & & \\
\hline \multirow{2}{*}{ Communication } & Experimental group & $2.62(0.74)$ & $3.14(0.58)$ & $3.15(0.13)$ & \multirow{2}{*}{6.70} & \multirow{2}{*}{$0.029^{*}$} \\
\hline & Control group & $2.64(0.47)$ & $2.67(0.50)$ & $2.66(0.13)$ & & \\
\hline \multirow{2}{*}{ Active consideration } & Experimental group & $2.50(0.82)$ & $3.14(0.62)$ & $3.31(0.15)$ & \multirow{2}{*}{8.51} & \multirow{2}{*}{$0.017^{*}$} \\
\hline & Control group & $2.17(0.73)$ & $2.30(0.57)$ & $2.41(0.15)$ & & \\
\hline \multirow{2}{*}{ Attempt to approach } & Experimental group & $2.97(0.75)$ & $3.37(0.61)$ & $3.29(0.12)$ & \multirow{2}{*}{8.32} & \multirow{2}{*}{$0.018^{*}$} \\
\hline & Control group & $2.77(0.63)$ & $2.70(0.57)$ & $2.77(0.12)$ & & \\
\hline \multirow{2}{*}{ Sharing } & Experimental group & $2.56(0.77)$ & $3.00(0.51)$ & $2.83(0.18)$ & \multirow{2}{*}{3.38} & \multirow{2}{*}{0.099} \\
\hline & Control group & $2.11(0.83)$ & $2.17(0.91)$ & $2.33(0.18)$ & & \\
\hline \multirow{2}{*}{ Empathy } & Experimental group & $2.46(0.45)$ & $2.96(0.45)$ & $2.65(0.15)$ & \multirow{2}{*}{2.33} & \multirow{2}{*}{0.161} \\
\hline & Control group & $1.83(0.51)$ & $1.96(0.69)$ & $2.27(0.15)$ & & \\
\hline \multirow{2}{*}{ Overall } & Experimental group & $2.63(0.66)$ & $3.13(0.47)$ & $3.01(0.10)$ & \multirow{2}{*}{11.27} & \multirow{2}{*}{$0.008^{* *}$} \\
\hline & Control group & $2.31(0.63)$ & $2.36(0.60)$ & $2.49(0.10)$ & & \\
\hline
\end{tabular}

${ }^{* * * *}$ Significant at $\mathrm{p}<0.05, \mathrm{p}<0.01$, by ANCOVA.

\begin{tabular}{|c|c|c|c|c|c|c|}
\hline Division & E1 & E2 & E3 & E4 & E5 & E6 \\
\hline Beginning & & & & & & \\
\hline End & & & & & & \\
\hline
\end{tabular}

Fig. 1. The change of operation result by each child (task: making a smiling face). 
squeezing woodwork bonds to fit the lines, tearing and adhering leaves, making a smiling face with sunflower seeds inside a sponge cake and so on. Later, there was a overall improvement and movements become more refined than in the beginning.

Figure 1 displays photos for each participant (E1-E6) as a means of individual comparison of their performance at the initial stage and at the final concluding stage.

\section{3) Participation in social activities}

At the initial stage participant E1 and E3 had problem with communication and understanding how to play; some children hardly participated in activities. They also showed low concentration in activities due to a distracting atmosphere. Later, they showed increased concentration in the program and communicated more.

\section{Conclusion}

This study applied the Forest Activities program to determine if forest activities provide a positive effect on low motor skills (GMS, FMS) and low prosocial behavior for children with a developmental disability from a specialized school. Completion of the program confirmed several changes, they are discussed below.

First, the MSTB-B results show a statistically significant improvement in the flexibility and balance of the experimental group, while the control group showed an increase in quickness.

Second, after the application of the program, fine motor skills were seen to increase within the experimental group, while the control group showed less rate of change. The experimental group's result was shown to be statistically significant in all sectors, such as accuracy and stability, but not in rapidity. This positive result suggests that this is due to efforts in providing a repetitive activity where participants made faces to gradually shrinking objects.

Third, the result of the experimental group's pre-post PBSYC test showed an increase in their prosocial behavior abilities compared to the results from the control group. The result for the experimental group turned out to be statistically significant within 5 sections $(\mathrm{p}<0.05)$ out of a total 7; these were leadership, providing assistance, communication, empathy, and attempt to approach.

In summary, the results of this research is in accordance with existing research which shows that recreational activities can bring out positive effects in the exercise ability of children with a developmental disability (Hwang, 2010) and children with experiences of nature can gain prosocial behaviors while communicating with peers (Kim, 2005). This has positive effects in prosocial activities such as providing assistance, consideration, and cooperation (Hong, 2009). This study supports the use of forest activities to assist children with developmental disabilities as a means of rehabilitation therapy.

\section{References}

Cho, I.S. 1999. Vocation guide of developmental disabilities. Myeongsung Press, Seoul, Korea.

Choi, J.O. and J.H. HA. 2002. Effects on improving the physical adjustment ability of the mentally retarded through ropeskipping. J. Special Children Educ. Res. 4(1):35-55.

Hong, J.J. 2009. The affect on the infant prosocial behavior and nature-friendly attitude from the games and activities in natural experience. MS thesis, Sungshin Women's Univ., Seoul, Korea.

Hwang, K.H. 2010. Effects of the play-oriented gross motor exercise program on the athletic ability of mentally retarded adolescents. MS thesis, Chungnam Univ., Daejeon, Korea.

Kang, B.D. 2002. A study of young children's gross-motor and finemotor skill development. MS thesis, Chungang Univ., Seoul, Korea.

Kim, S.Y. 2005. The walk activity of children into the woods and the stay. MS thesis, Chungang Univ., Seoul, Korea.

Kim, Y.O. 2003. A study on the development of prosocial behavior scale for young children. Korean Children's Acad. 24(5):105-118.

Lee, M.J. 2011, Effects of horticultural therapy on social skill and self-expression of the intellectually challenged people. J. Korean Soc. People Plants Environ. 14(4):199-205.

Lim, J.H. and K. Y.C. 2005. The effects of art therapy for development handicapped child with self expression and relationship. J. Mental Retardation 7:173-191.

Noh, M.H. 2009. The influence of the STAD (Student Teams Achievement Division) cooperative learning on the intellectually disabled students' class participation behaviors and relationship with the highschool students. MS thesis, Changwon Univ., Changwon, Korea.

Park, B.J. 2014. Eco healing magazine 1:18-21.

Park, H.M. 1993. Movement skill test battery. Publishing special education, Seoul, Korea.

Park, M.A. 2007. The effective of collaborative art activity on pro-social activity and self -concept of young children. MS thesis, Kwangju Woman's Univ., Kwangju, Korea.

Yoo, K.S. 2001. A comprative study on the behavioral characters of the general and accommodated children. MS thesis, Wonkwang Univ., Iksan, Korea. 